\title{
Clinical significance of measuring plasminogen activator inhibitor-1 in sepsis
}

Toshiaki Iba ${ }^{1 *}$ and Jecko Thachil ${ }^{2}$

\begin{abstract}
Background: Disseminated thrombotic process in the microcirculation is considered to be an important cause of multiple organ dysfunction in sepsis. The fundamental purpose of this prothrombotic change was believed to be in the host defense against microbial dissemination. In that process, antifibrinolytic property plays an important role.

Main body: For the understanding of pathophysiology of sepsis, it is quite useful to grasp the alterations in coagulation/fibrinolytic parameters, i.e., plasminogen activator and plasminogen activator inhibitor-1. They play crucial roles in the development of clot formation and disseminated intravascular coagulation that leads to fatal organ dysfunction. Basically, fibrinolysis is a simple system compared to the complex coagulation cascade. Plasmin is the only factor that regulates fibrinolysis, and this enzyme is modulated by several factors including plasminogen activators and plasminogen activator inhibitor-1. However, recent studies have elucidated the complex regulation of the production, activation, and inactivation of these fibrinolytic factors.
\end{abstract}

Conclusion: The dynamic change of the fibrinolytic system plays a crucial role in the pathophysiology of sepsis. In this commentary, we introduce the recent advances of the research regarding fibrinolytic system.

Keywords: Sepsis, Plasminogen activator inhibitor-1, Disseminated intravascular coagulation

\section{Background}

It is well known that fibrin removal is severely hindered by inactivation of the endogenous fibrinolytic system, mainly as a result of upregulation of plasminogen activator inhibitor type-1 (PAI-1). Consequent increased fibrin generation and impaired fibrin breakdown leads to deposition of clots in the microvasculature, leading to the tissue ischemia and ensuing organ dysfunction. Numerous experimental and clinical studies have revealed that the levels of PAI-1 but not tissue plasminogen correlated with the outcome and severity of multiple organ dysfunction in sepsis and disseminated intravascular coagulation (DIC) [1]. Hence, it is widely accepted that PAI-1 can be a useful biomarker for evaluating the severity of sepsis. Furthermore, the over-suppression of fibrinolysis caused mainly by PAI- 1 constitutes an important target for therapy in patients with sepsis and DIC [2]. In the former issue of Journal of Intensive Care, Hoshino et al.

\footnotetext{
* Correspondence: toshiiba@juntendo.ac.jp

${ }^{1}$ Department of Emergency and Disaster Medicine, Juntendo University Graduate School of Medicine, 2-1-1 Hongo Bunkyo-ku, Tokyo 113-8421, Japan

Full list of author information is available at the end of the article
}

[3] reported the clinical significance of measuring total PAI-1 antigen in sepsis in their retrospective observational study. Here, we introduce the accumulated knowledge with respect to this issue.

\section{Main body}

PAI-1, a 48-kDa serine proteinase inhibitor (SERPIN), produced by various cells such as vascular endothelial cells, platelets, smooth muscle cells, fibroblasts, adipose tissue, and monocytes/macrophages [4], is the main physiological plasminogen activator inhibitor. Like other SERPINs, PAI-1 inhibits its target proteinases, tissue-type plasminogen activator, and urokinase-type plasminogen activator by the formation of a 1:1 stoichiometric reversible complex [5]. PAI-1 can occur in various molecular forms in blood, including active PAI-1 (mainly PAI-1 complexed with vitronectin), inactive or latent PAI-1 (mainly present in lysed platelets and dominant in serum), and PAI-1 complexed with its target proteases (urokinase-type plasminogen activator and tissue-type plasminogen activator). There are several commercialized kits available to detect PAI-1 antigen, and thus, appropriate selection of the kit depending on the purposes is important [6]. 
Currently, we also can assess the PAI-1 activity, and this will be more suitable to detect the fibrinolytic activity rather than the total produced volume or distribution of PAI-1.

Since the production of PAI-1 is regulated by pro- and anti-inflammatory cytokines such as interleukin-1 $\beta$, interleukin 6 , and transforming growth factor- $\beta$, its relation to the inflammatory responses has been strongly assumed [7]. In pathogenesis of sepsis, PAI-1 plays a role in several biological processes dependent on the inhibition of plasminogen activators and plasmin activity [5]. As a consequence, overproduction of PAI-1 may contribute to organ dysfunction in patients suffering from severe infection and DIC.

The fibrinolytic system is much simpler compared to the complexity of the coagulation system. Basically, plasmin is the only activator of fibrinolysis, and the balance between tissue plasminogen activator and PAI-1 mainly regulates plasmin activity. Thrombin-activatable fibrinolysis inhibitor (TAFI) and neutrophil elastase also have the capability to modulate fibrinolysis, but the pathophysiological roles of these factors have not been fully elucidated. Dynamic changes in fibrinolytic status are crucially involved in the pathogenesis of DIC and multiple organ dysfunction in sepsis [8]. Recent evidences indicate that physical entrapment of microbes by fibrin at the site of infection may limit their capacity to disseminate into the systemic circulation. Under these circumstances, impairment of fibrinolysis contributes to the protective role in host defense [9].

In healthy human volunteers, endotoxin infusion induces a rapid change in the coagulation system. Inflammatory cytokines such as tumor necrosis factor and interleukin-6 rose within 120 min with a concurrent rise in the plasminogen activators, indicating endothelial activation. Within $150 \mathrm{~min}$, these changes are counteracted by an even greater and sustained rise in PAI-1 leading to clot longevity [10]. These observations suggest that both activated endothelial cells and platelets cooperate to induce a thrombotic state by producing PAI- 1 . Finally, the reduction in activated protein $\mathrm{C}$ because of reduced availability of thrombomodulin may also play a role in decreased fibrinolysis. Less activated protein $\mathrm{C}$ is available to inhibit PAI-1, thus augmenting clot stability.

The clinical significance of measuring PAI-1 in sepsis has been actively studied since 1990s, and it has been repeatedly reported that the elevated PAI-1 levels was associated with an unfavorable outcome in sepsis $[11,12]$. Previously, Koyama et al. [13] measured various coagulation/fibrinolysis markers in sepsis patients and reported that thrombin-antithrombin complex (TAT), PAI-1, and protein $\mathrm{C}$ discriminated well between patients with and without overt DIC (area under the receiver operating characteristic curve [AUROC], 0.77, 0.87 and 0.85, respectively) and, using the three together, significantly improved the AUROC up to 0.95. Amongst the significant diagnostic markers for overt DIC, TAT and PAI-1 were the best predictors of 28-day mortality (AUROC, 0.77 and 0.81 , respectively). Following similar reports, Hoshino et al. [3] reported that the elevated levels of PAI-1 was associated with the poor outcome and the AUROC for 28-day mortality was 0.72 , and the optimal cutoff level was $83 \mathrm{ng} / \mathrm{mL}$. What were unique in their observations were firstly, only PAI-1 but no other coagulation markers such as TAT, plasmin-plasmin inhibitor complex, protein $\mathrm{C}$, thrombomodulin, and soluble fibrin were associated with mortality. Secondly, the optimal cutoff was $83 \mathrm{ng} / \mathrm{mL}$ [reference range $<50 \mathrm{ng} / \mathrm{mL}$ ], and that was extremely lower than the previous reports. The detail was not discussed, but these results were a little bit surprising to us. Aforementioned molecular markers and anticoagulants have been repeatedly reported as useful severity markers $[14,15]$. One possible reason for the discrepancy is the timing of sampling. Since the coagulation/fibrinolytic change is a dynamic process, the sampling should not be just "ICU admission" but should be specified like the timing from the onset. To make the report more informative, we also would like to suggest to add newer techniques like thromboelastography. Rotational thromboelastography (TEG) and thromboelastometry (ROTEM) are point-of-care tests, which evaluate wholeclot formation and dissociation. It was reported that decreased fibrinolytic activity, as reflected by the lysis index, was found to discriminate the severe cases [16].

In contrast to the regulation of PAI-1, less is known about the plasminogen activation system, its maintenance should be precisely regulated, but the detail still remains to be clarified. Microorganisms including bacteria, fungi, and parasites have been proven to interact in a specific manner with the components of fibrinolysis regulators, i.e., pathogenic microorganisms are capable to destabilize the function of proteases, activators, or inhibitors of fibrinolysis to disseminate in the host and evade from the immune response [17].

Regarding the fibrinolytic system, some other components are known to relate to its function. For example, TAFI plays an important role in the inhibition of fibrinolysis [18]. PAI-2 also inhibits the fibrinolysis and is reported to increase in non-survivors of sepsis [19]. Based on the above knowledge, not only the measurement of fibrinolysis inhibitors but the comprehensive evaluation including activators of fibrinolysis would be important for the accurate understanding of pathophysiology of sepsis.

\section{Conclusion}

It has been clarified that changes of coagulation/fibrinolytic status are deeply related to the development of septic organ dysfunction. Since the status changes dynamically 
and varies significantly depending on the patients' condition, comprehensive evaluation is necessary to understand this delicate and complex situation. Based on the accumulated knowledge, we do not recommend the one-point PAI-1 antigen analysis but recommend the sequential analysis of the multi-factors for the accurate assessment of coagulation/fibrinolytic systems. This careful approach may avoid misleading the future studies in this area.

\section{Abbreviations \\ AUROC: Area under the receiver operating characteristic curve; \\ DIC: Disseminated intravascular coagulation; PAI-1: Plasminogen activator inhibitor type 1; SERPIN: Serine proteinase inhibitor; TAFI: Thrombin- activatable fibrinolysis inhibitor; TAT: Thrombin-antithrombin complex}

\section{Acknowledgements}

Not applicable.

\section{Funding}

No funding is provided to this commentary.

\section{Availability of data and materials}

Not applicable.

\section{Authors' contributions}

TI drafted and JT edited the manuscript. Both authors approved the final manuscript.

\section{Ethics approval and consent to participate}

Not applicable.

\section{Consent for publication}

Not applicable.

\section{Competing interests}

The authors declare that there are no competing interests.

\section{Publisher's Note}

Springer Nature remains neutral with regard to jurisdictional claims in published maps and institutional affiliations.

\section{Author details}

${ }^{1}$ Department of Emergency and Disaster Medicine, Juntendo University Graduate School of Medicine, 2-1-1 Hongo Bunkyo-ku, Tokyo 113-8421, Japan. ${ }^{2}$ Department of Haematology, Manchester Royal Infirmary, Manchester, UK.

Received: 9 August 2017 Accepted: 30 August 2017

Published online: 06 September 2017

\section{References}

1. Hack CE. Fibrinolysis in disseminated intravascular coagulation. Semin Thromb Hemost. 2001;27:633-8.

2. Asakura H, Ontachi Y, Mizutani T, Kato M, Saito M, Kumabashiri I, Morishita E, Yamazaki M, Aoshima K, Nakao S. An enhanced fibrinolysis prevents the development of multiple organ failure in disseminated intravascular coagulation in spite of much activation of blood coagulation. Crit Care Med. 2001;29:1164-8.

3. Hoshino K, Kitamura T, Nakamura Y, Irie $Y$, Matsumoto N, Kawano $Y$, Ishikura $H$. Usefulness of plasminogen activator inhibitor-1 as a predictive marker of mortality in sepsis. J Intensive Care. 2017:5:42.

4. Brogren H, Sihlbom C, Wallmark K, Lönn M, Deinum J, Karlsson L, Jern S. Heterogeneous glycosylation patterns of human PAI-1 may reveal its cellular origin. Thromb Res. 2008;122:271-81.

5. Lijnen HR. Pleiotropic functions of plasminogen activator inhibitor-1. J Thromb Haemost. 2005;3:35-45.
6. Meijer P, Pollet DE, Wauters J, Kluft C. Specificity of antigen assays of plasminogen activator inhibitor in plasma: Innotest PAl-1immunoassay evaluated. Clin Chem. 1994;40:110-5.

7. Healy AM, Gelehrter TD. Induction of plasminogen activator inhibitor-1 in HepG2 human hepatoma cells by mediators of the acute phase response. J Biol Chem. 1994;269:19095-100.

8. Gando S. Role of fibrinolysis in sepsis. Semin Thromb Hemost. 2013;39:392-9.

9. Engelmann B, Massberg S. Thrombosis as an intravascular effector of innate immunity. Nat Rev Immunol. 2013;13:34-45.

10. van Deventer SJ, Büller HR, ten Cate JW, Aarden LA, Hack CE, Sturk A. Experimental endotoxemia in humans: analysis of cytokine release and coagulation, fibrinolytic, and complement pathways. Blood. 1990;76:2520-6.

11. Mesters RM, Florke N, Ostermann H, Kienast J. Increase of plasminogen activator inhibitor levels predict outcome of leukocytopenic patients with sepsis. Thromb Haemost. 1996:75:902-7.

12. Leithäuser B, Matthias FR, Nicolai U, Voss R. Hemostatic abnormalities and the severity of illness in patients at the onset of clinically defined sepsis. Possible indication of the degree of endothelial cell activation? Intensive Care Med. 1996;22:631-6.

13. Koyama K, Madoiwa S, Nunomiya S, Koinuma T, Wada M, Sakata A, Ohmori T, Mimuro J, Sakata Y. Combination of thrombin-antithrombin complex, plasminogen activator inhibitor-1, and protein $\mathrm{C}$ activity for early identification of severe coagulopathy in initial phase of sepsis: a prospective observational study. Crit Care. 2014;18:R13.

14. Iba T, Kidokoro A, Fukunaga M, Sugiyama K, Sawada T, Kato H. Association between the severity of sepsis and the changes in hemostatic molecular markers and vascular endothelial damage markers. Shock. 2005;23:25-9.

15. Iba T, Gando S, Murata A, Kushimoto S, Saitoh D, Eguchi Y, Ohtomo Y, Okamoto K, Koseki K, Mayumi T, Ikeda T, Ishhikura H, Ueyama M, Ogura Y, Endo S, Shimazaki S. Predicting the severity of systemic inflammatory response syndrome (SIRS)-associated coagulopathy with hemostatic molecular markers and vascular endothelial injury markers. J Trauma. 2007:63:1093-8

16. Müller MC, Meijers JC, Vroom MB, Juffermans NP. Utility of thromboelastography and/or thromboelastometry in adults with sepsis: a systematic review. Crit Care. 2014;18:R30.

17. Bergmann S, Hammerschmidt S. Fibrinolysis and host response in bacterial infections. Thromb Haemost. 2007;98:512-20.

18. Zeerleder S, Schroeder V, Hack CE, Kohler HP, Wuillemin WA. TAFI and PAI-1 levels in human sepsis. Thromb Res. 2006;118:205-12.

19. Robbie LA, Dummer S, Booth NA, Adey GD, Bennett B. Plasminogen activator inhibitor 2 and urokinase-type plasminogen activator in plasma and leucocytes in patients with severe sepsis. Br J Haematol. 2000;109:342-8.

Submit your next manuscript to BioMed Central and we will help you at every step:

- We accept pre-submission inquiries

- Our selector tool helps you to find the most relevant journal

- We provide round the clock customer support

- Convenient online submission

- Thorough peer review

- Inclusion in PubMed and all major indexing services

- Maximum visibility for your research

Submit your manuscript at www.biomedcentral.com/submit 